\title{
Soxhlet Extraction of Crotalaria Juncea Oil Using Cylindrical and Annular Packed Beds
}

\author{
Ratna Dutta, Ujjaini Sarkar, and Alakananda Mukherjee
}

\begin{abstract}
An innovative method for the extraction of vegetable oils, from Crotalaria Juncea seeds, was developed, using suitable solvent in a modified Soxhlet apparatus. The present study describes the general extraction mechanism in modified Soxhlet apparatus and change of mass transfer extent within fixed duration with the change of the shape of packed bed used as a seed holder. Regular cylindrical and annular shaped seed holders were used along with irregular (elliptical) shaped seed holder. Maximization of mass transfer parameter in the up flow regime gave considerable increase in the yield of oil production. Use of annular seed holder gives maximum driving force for the up flow regime and higher mass transfer area, hence improved yield.
\end{abstract}

Index Terms-Annular packed bed, mass transfer regimes, modified soxhlet extractor, crotalaria juncea oil.

\section{INTRODUCTION}

Soxhlet based solvent extraction process is the primary means of extracting vegetable oil from oleaginous materials. Crushed oil seeds are put in a packed bed which is in contact with pure solvent for the oil to be transferred from the solid matrix to fluid medium. A particular solvent is chosen, based on the maximum leaching characteristics of the desired solute. The mass transfer that occurs during solvent extraction in a packed column was analyzed [1]-[3]. There is a large amount of work mentioned in the literature [4]-[7], dealing with leaching of bio products from solid with liquid solvents. Bio-oil extracted from Crotalaria Juncea seeds is a promising bio-fuel oil [8]. This promotes the research interest to modify the Soxhlet extraction process [9] in order to maximize the oil yield.

The main objective of this piece of research work is to elucidate the extraction process by experiments to understand the various flow regimes developed during the process and effect of shape of the packed bed on the oil extraction yield by improving extraction rate. Normal cylindrical and annular seed holders along with irregular elliptical filter paper bed were used for comparison. Change of oil extraction rate was also observed by identifying the change of the physical properties of the oil-solvent mixture.

\section{EXPERIMENTAL}

\section{A. Extraction of Crotalaria Juncea Oil in Modified Soxhlet Apparatus}

In this work, solvent extraction was done in a modified
Soxhlet apparatus for the production of Crotalaria Juncea oil from the crushed seeds. In a Soxhlet apparatus, the extractor thimble is fitted in between a round bottom flask at the bottom and a bulb condenser at the top. Inside the thimble holder, solid matrix of seeds is wrapped within a packing. Normally, with an appropriate design, the condensed solvent vapour accumulates inside the extractor. Here, the solvent comes in contact with the seeds and oil is leached out. When the condensate moves down through the bed of seeds, mass transfer takes place. However, major amount of mass transfer of oil from the seeds to solvent occurs when the accumulated solvent moves up within the annulus purely due to the hydrostatic pressure head. So combined effect of through circulation and cross circulation of the solvent with respect to the seed bed is reflected in the total extent of mass transfer from solid to liquid. So, surface area offered by the bed and the seed-solvent contact time are the two major factors for the yield of oil production. Generally, seed holders are made by filter paper, having irregular elliptical structure.

In a modified Soxhlet extractor, shape of the seed holders was amended. Regular cylindrical and annular shapes were tried and investigated for finding effect of shape.

Both modified seed holders were made by wire-mesh having one end sealed. Cylinder shaped holder had ID: $5 \mathrm{~cm}$, OD: $5.4 \mathrm{~cm}$ and length: $33 \mathrm{~cm}$ whereas annular shape had two cylinders, with outer one having same dimension as before and the inner cylinder had ID: $2 \mathrm{~cm}$ and length: $33 \mathrm{~cm}$. Annular portions was used to hold seeds. These seed holders can be accommodated in a standard Soxhlet extractor having a solvent capacity of 3lt. All the experimental runs were carried out for a duration within which three times siphoning out of solvents occurred. At the end of a batch run, the packed bed of seeds was removed and afterwards the oil-solvent mixture is distilled further by simple batch distillation followed by separation of the mixture using a rotary evaporator apparatus (Make: BUCHI; Model: Rotavapor $\mathrm{R}-3)$. The extractions were performed in triplicate and their mean values and standard deviations were calculated. The percentage yield is calculated on the basis of the following equation with $\mathrm{W}_{1}$ being the amount of seed taken in gm and $\mathrm{W}_{2}$ being the amount of oil produced in $\mathrm{gm}$.

$$
\% \text { Oil Yield }=\left(W_{2} / W_{1}\right) \times 100 .
$$

Oil yield in two cases using regular cylindrical seed holder and annular seed holder were compared with normal irregular shaped elliptical bed (made by filter paper).

\section{THEORY}

\section{A. General Extraction Mechanism}

More or less three distinct mass transfer steps are to be
Manuscript received May 16, 2014; revised July 12, 2014.
Ratna Dutta was with the Jadavpur University, India (e-mail: paul.ratna@gmail.com). 
followed during extraction of oil from plant seeds [10], [11]: a) transport of the oil component through the pores of the matrix (intra-particle diffusion), b) diffusion through the stagnant liquid film present outside the solid seed (external diffusion) and c) removal of the oil component from a solid matrix by thermodynamic partitioning into the adjacent flowing solvent.

Importance of the steps is judged by noting the variation of extraction yield with change of condensed solvent flow rate, solvent volume and contact time. If the intra-particle diffusion step is controlling one, then extraction rate and yield will not depend on bulk solvent flow rate. If extraction is controlled by external film transfer diffusion, extraction rate increase with solvent flow rate. On the other hand, where the extraction is controlled by thermodynamic partitioning, doubling the bulk fluid flow rate would double the extraction rate.

Since, in a Soxhlet extractor bulk solvent flow rate is available due to flow of condensed solvent at isothermal condition, so; superficial velocity in the bed remains same in all runs but interstitial velocity through the bed may be varied due to variation in porosity of the bed. Bed porosity can be varied only by varying size fraction of the crushed seeds. Mass transfer controlling step can be chosen in the down flow regime by varying porosities of the bed and that can be used for determining the controlling step for the overall mass transfer. Since down flow regime is short on duration; up flow regime will offer major share in obtaining the amount of mass transfer which solely depends thermodynamic partitioning with external mass transfer.

\section{B. Two flow Regimes within Soxhlet Extractor: Qualitative Analysis}

In Soxhlet extractor, condensed solvent falls on the bed, which aids the extraction (at its boiling point temperature) at isothermal and isobaric condition. Mass transfer occurs during two circulations of the solvent; firstly, by downpour of the solvent and secondly, by up flow of the solvent under hydrostatic pressure head. These two mass transfer regimes are acting in series combination and yield of oil production greatly depends on duration of the specific regimes and mass transfer area available in both the cases.

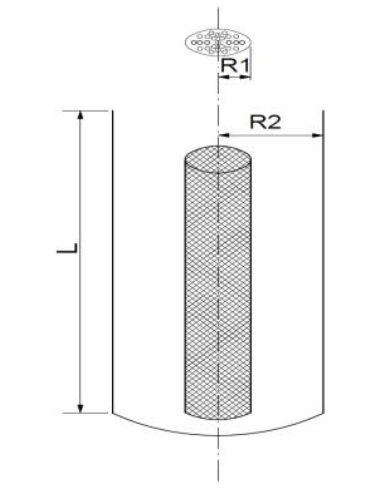

Fig. 1. Normal Cylindrical Bed

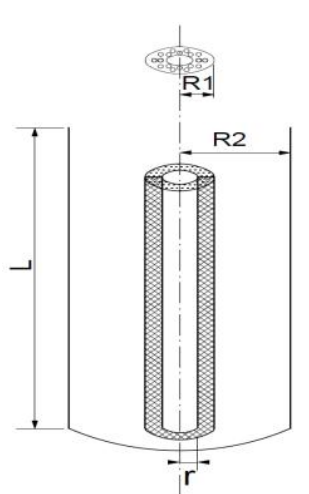

Fig. 2. Annular bed.

\section{RESULTS AND DISCUSSIONS}

\section{A. Effect of Parameters on Extraction Process}

\section{1) Flow rate of solvent}

Flow rate has direct influences on the mode of mass transfer for the extraction system. To categorize the mass transfer mechanism, porosities of the bed was changed to vary interstitial velocity of the solvent through the bed. Some measured amount of oil-free materials was randomly mixed with crushed seed within the packed bed to change the porosity of the bed. Since, extraction yield was changing with porosities (Table I) and more specifically with interstitial velocity, so external diffusion mechanism played an important role. It was found that yield of oil production is decreasing with increase of velocity, which is just due to the lower residence time of the solvent within the bed.

\begin{tabular}{ccc}
\multicolumn{2}{c}{ TABLE I: YIELD OF OIL PRODUCTION FOR VARYING POROSITIES OF BED } \\
\hline Porosity of bed & $\begin{array}{c}\text { Interstitial velocity } \\
\text { cm.min }^{-1}\end{array}$ & Oil yield (\%) \\
\hline 0.561 & 0.0151 & 4.3716 \\
0.450 & 0.0166 & 2.9811 \\
0.380 & 0.0175 & 1.9710
\end{tabular}

Bed: cylindrical, crushed seed weight: 200 gm, solvent volume taken: 2lt, size fraction: $(-8 /+18)$ mesh, duration of extraction: 3 times siphoning.

\section{2) Effect of specific surface area of solid substrate in bed}

Specific surface area of solid substrate in bed acts as mass transfer area for oil transfer in the first regime. Specific surface area of a solid substrate particle in a packed bed $\left(a_{P}\right)$ is generally describes the ratio of effective inner area of the bed for mass transfer to total volume of the bed. From the Fig. 1 and Fig. 2, it is evident that keeping same outer radius, change of the effective bed radius changes effective surface area of solid substrate for mass transfer. In cylindrical shaped bed, inner area is function of $R 1$ only; but, in annular shaped bed, it is function of $(R 1-r)$. Hence in order to accommodate same amount of seeds, higher bed height was approached in annular shaped seed holder, giving lower $a_{P}$ value with the same porosity of the bed. This area, $a_{P}$ determines the amount of mass transfer in down flow regime only. Obviously, as $a_{P}$ increases, rate of mass transfer increases, hence yield of oil production increases. Though, $a_{P}$ was more in normal cylindrical bed, but effect of that on oil yield was not so great because of shorter duration of that regime compared to the total extraction time (Table II).

\section{3) Effect of shape of the bed}

Specific surface area of the bed acts as the mass transfer area for oil transfer during up flow of solvent. Shape has great effect on specific surface area of solid bed $\left(a_{s}\right)$, which has significant role in changing the yield of oil production. Two regular shapes of seed holders were used in this work and their performance (based on yield of oil production) were compared with traditional irregular elliptical shaped filter paper bed. Since, $a_{s}$ is the mass transfer area for up flow regime, so as this increased, rate of mass transfer increased and gave higher yield. Combined effect of higher $a_{s}$ and higher duration of up flow regime (since bed height is higher) gave highest yield in case of the use of annular shaped seed holder. In normal cylindrical seed holder, one cylindrical surface area having radius $2.7 \mathrm{~cm}$ and $13.7 \mathrm{~cm}$ height was acting $a_{s}$. But, in annular seed holder, two cylindrical surface areas were available; one having radius $2.7 \mathrm{~cm}$, height 21.3 $\mathrm{cm}$ and second having $1 \mathrm{~cm}$ radius and $21.3 \mathrm{~cm}$ height. Experimentally, it was found (reflected in Table II) that the 
regular annular shaped bed works most efficiently though its interstitial velocity. performance is somewhat offset by lower $a_{p}$ and lower

TABLE II: EFFECT OF SHAPE OF SEED HOLDER ON OIL YIELD

\begin{tabular}{|c|c|c|c|c|c|c|c|}
\hline Bed Shape & $\begin{array}{l}\text { Bed height, } \\
\text { L (cm) }\end{array}$ & $a_{P}{ }^{*}\left(\mathrm{~cm}^{-1}\right)$ & $a_{s} * *\left(\mathrm{~cm}^{-1}\right)$ & $\begin{array}{l}\text { Down flow } \\
\text { duration (sec) }\end{array}$ & $\begin{array}{l}\text { Up flow } \\
\text { duration } \\
\text { (sec) }\end{array}$ & $\begin{array}{l}\text { Interstitial } \\
\text { velocity } \\
(\mathrm{cm} / \mathrm{sec})\end{array}$ & $\begin{array}{l}\text { Oil yield } \\
(\%)\end{array}$ \\
\hline $\begin{array}{l}\text { Elliptical } \\
\text { (Irregular) }\end{array}$ & 16.1 & - & - & 65 & 2160 & 0.0135 & 2.95 \\
\hline $\begin{array}{l}\text { Cylindrical } \\
\text { (Regular) }\end{array}$ & 13.7 & 0.0320 & 0.886 & 58 & 1560 & 0.0151 & 6.53 \\
\hline $\begin{array}{l}\text { Annular } \\
\text { (Regular) }\end{array}$ & 21.3 & 0.0206 & 2.829 & 36 & 1851 & 0.0136 & 7.51 \\
\hline
\end{tabular}

$* a_{p}$ is calculated by inside solid area of the bed to volume of the bed

$* * a_{s}$ is calculated by outer surface area of the bed to volume of bed

Duration of Extraction: 3 times siphoning, Seed weight Taken: around 200 gm, Solvent volume taken: 2 lt, Size fraction: (-8/+18) mesh and superficial velocity of solvent: $0.0111 \mathrm{~cm} / \mathrm{sec}$.

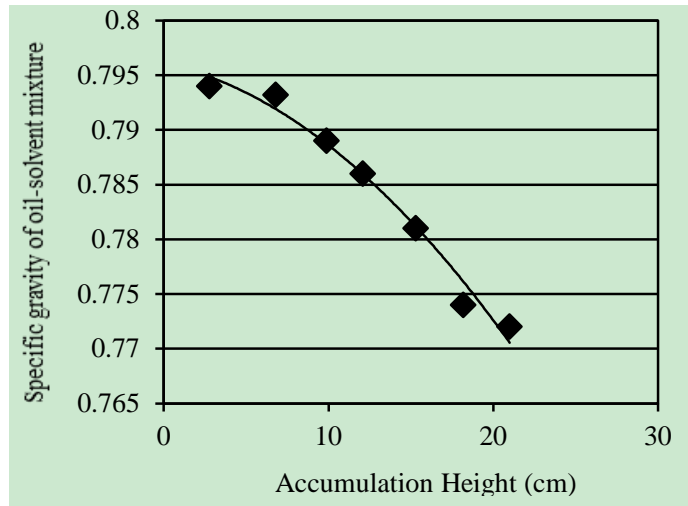

Fig. 3. Variation of density of oil-solvent mixture with Accumulation height. Seed Holder Type: Cylindrical, Bed Height: $13.7 \mathrm{~cm}$, Specific gravity of pure 2-propanol: 0.78

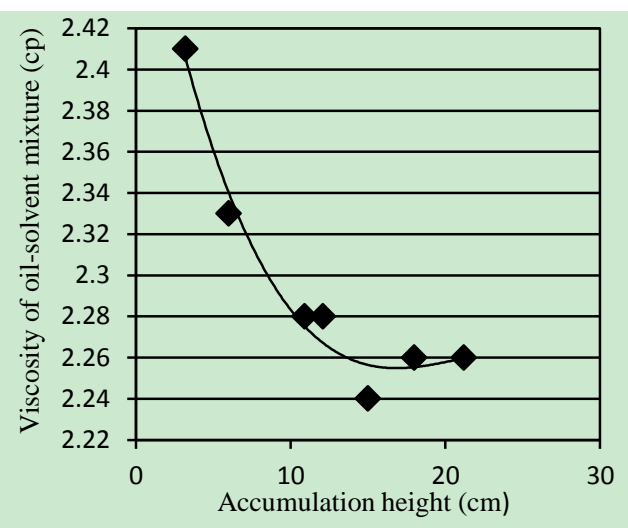

Fig. 4: Variation of viscosity of oil-solvent Mixture with accumulation.

Height Using Viscometer MAKE: Brookfield viscometer, MODEL: DV-I, with Enhanced UL Adapter no.: M06-084, Speed 50 rpm

\section{B. Equilibrium between Solid and Solvent}

Generally, higher extraction yield is achievable at the start of the process when the pure solvent extracts the free oil originating from the pores of the crushed seed and end of the process, extraction is more difficult probably due to diffusion through the pores [12] and ultimately becomes insignificant. This has also occurred in this study. Lower amount of oil recovery in the solvent was observed with increase of up flow duration. Lower oil production decreases density and viscosity of the oil-solvent mixture which is reflected in Fig. 3 and Fig. 4. Change of density and viscosity with accumulation height in the up flow regime was very prominent in annular shaped seed holder.

\section{CONCLUSION}

Since, down flow regime is comparatively very short than up flow regime in any case, so; maximization of mass transfer parameter which gives increase in mass transfer rate for up flow regime will give considerable increase in yield of oil production. Regular shaped of seed holder is always preferred for better extraction yield. Use of annular shaped seed holder gave lower down flow time, higher driving force for up flow regime, higher duration of the period and above all higher $a_{s}$; resulted higher yield. So, use of effective shape of the seed holder may improve yield of oil production by improving extraction rate.

\section{REFERENCES}

[1] M. L. M. N. N. Cerutti, A. A. U. Souza, and S. M. A. G. U. Souza, "Solvent extraction of vegetable oils: Numerical and experimental study," Food and Bioproducts Processing, vol. 90, pp. 199-204, 2012.

[2] R. C. Oliveira, S. T. D. Barros, and M. L. Gimenes, "Extraction of passion fruit oil with green solvent," J. Food engineering, vol. 117, no. 4, pp. 458-463, 2013.

[3] C. H. Chan, R. Yusoff, and G. C. Ngoh, "Modelling and kinetic study of conventional and assisted batch solvent extraction," Chem. Engg. Research and Design, October, 2013.

[4] M. K. Abu-Arabi, M. A. Allawzi, H. S. Al-Zoubi, and A. Tamimi, "Extraction of jojoba oil by pressing and leaching," Chem. Eng. J., vol. 76, pp. 61-65, 2000.

[5] E. Akbar, Z. Yaakob, S. K. Kamarudin, M. Ismail, and J. Salimon, "Characteristic and composition of JatrophaCurcas oil seed from Malaysia and its potential as biodiesel feedstock," European Journal of Scientific Research, pp. 396-403, 2009.

[6] P. N. Giannelos, F. Zannikos, S. Stournas, E. Lois, and G. Anastopoulos, "Tobacco seed oil as an alternative diesel fuel: physical and chemical properties," Industrial crops and products, vol. 16, pp. $1-9,2002$.

[7] P. N. Giannelos, S. Sxizas, E. Lois, F. Zannikos, and G. Anastopoulos, "Physical, Chemical and fuel related properties of tomato seed oil for evaluating its direct use in diesel engines," Industrial crops and products, vol. 22, pp. 193-199, 2005.

[8] R. Dutta, U. Sarkar, and A. Mukherjee, "Extraction of oil from crotalaria juncea seeds in a modified soxhlet apparatus: Physical and chemical characterization of a prospective bio-fuel," Fuel, vol. 116, pp. 794-802, 2014.

[9] M. D. Luque de Castro and F. Priego-Capote, "Soxhlet extraction: Past and present panacea," J Chromatogr A, vol. 1217, pp. 2383-2389, 2010 .

[10] M. Carrin and G. Craiste, "Mathematical modeling of vegetable oil solvent extraction in a multistage horinzontal extractor," J. Food Engineering, vol. 85, pp. 418-425, 2008.

[11] E. R. Baumler, A. A. Carelli, G. H. Crapiste, and M. E. Carrin, "Solvent extraction modeling of vegetable oil and its minor compounds," J. Food Engineering, vol. 107, pp. 186-194, 2011.

[12] G. C. Majumder, A. N. Samanta, S. P. Sengupta, "Modeling of solvent extraction of vegetable oil in packed bed," J. Am. Oil Chem. Soc., vol. 72, pp. 971-979, 1995. 


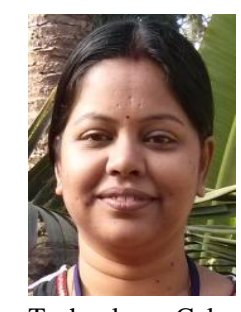

Ratna Dutta is an assistant professor in the Department of Chemical Engineering of Jadavpur University, Kolkata, India. She is also currently a research scholar in the same Department. She is pursuing her research under the guidance of Dr. Ujjaini Sarkar and Mr. Alakananda Mukherjee on Bio oil extraction from seeds using solvent extraction technique. She has completed her M.Tech. in chemica engineering from University College of Science and Technology, Calcutta University. Then, she joined in Heritage Institute of Technology, WBUT as a lecturer. Currently, her research interests include mass transfer processes and separation chemistry.

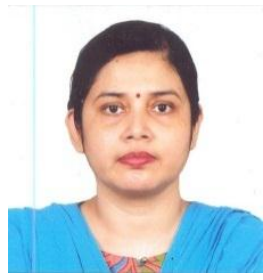

Ujjaini Sarkar is a chemical engineer by profession, holds a bachelor's degree in chemical engineering from Jadavpur University, Kolkata, India, a master's degree in chemical engineering from Indian Institute of Technology, Kanpur, UP, India and a doctoral degree $(\mathrm{PhD})$ in engineering from Cranfield University, United Kingdom.

She has work experience of 11 years as a design engineer in DASTURCO, a multi-national design consultancy firm. Her experience includes design of piping systems for various utility fluids and design, selection and procurement of air pollution control systems. Her research experience includes three post-doctora research experiences at USDA, BARC Facility, Maryland, USA, at the Chemical and Environmental Engineering Department, NUS, Singapore and Bio systems Engineering Department, Iowa State University. She has contributed in couple of Book Chapters published by RSC, United Kingdom, World Publishing, IEEE etc. She has authored 25 publications in refereed journals of international repute. She has carried out six scientific projects funded by National Agencies like ISRO, DST, UGC etc. Presently she has been awarded an UKIERI research funding.

She holds a professional membership of AOGS and Indian Institute of Chemical Engineers.

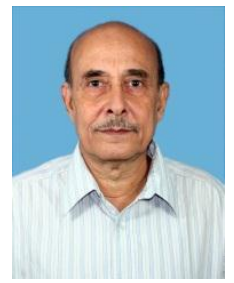

Alakananda Mukherjee is a professor of chemical engineering in Jadavpur University, Kolkata, India. $\mathrm{He}$ is experienced in modeling and simulation of chemical engineering and bioengineering processes.

His research interest ranges from cross transport phenomena through digital control of semi-batch reactor, biosensor, and solar hydrogen to bioenergy and bioremediation.

Prof. Mukherjee is a life member of Indian Association for the Cultivation of Science. 